\title{
Current status of cesarean section myomectomy-prospective ongoing study
}

\author{
Ripan Bala, Preet Kamal*, Madhu Nagapal, Sheena Singh
}

Department of Obstetrics and Gynecology, SGRDUHS, Vallah, Amritsar, Punjab, India

Received: 03 July 2019

Accepted: 17 July 2019

\section{*Correspondence:}

Dr. Preet kamal,

E-mail: Preetkamal1970@gmail.com

Copyright: (C) the author(s), publisher and licensee Medip Academy. This is an open-access article distributed under the terms of the Creative Commons Attribution Non-Commercial License, which permits unrestricted non-commercial use, distribution, and reproduction in any medium, provided the original work is properly cited.

\begin{abstract}
Background: The aim of the study was to assess the feasibility, safety and efficacy of performing myomectomy during cesarean section.

Methods: It was prospective study conducted in Sri Guru Ram Das University of Health and sciences which is a tertiary care referral centre. Myomectomy was conducted in 34 pregnant women during elective or emergency cesarean section. Analysis was done with reference to age, parity, character of myomas, intraoperative and postoperative morbidity, duration of surgery and duration of stay in hospital.

Results: In this study 34-58 fibroid of various size $(2-14 \mathrm{~cm})$ were removed in 34 patients during cesarean section. Majority of fibroids were located in body of uterus $(65.5 \%)$ and in anterior wall $(55.2 \%)$ and all them were sub serosal. No significant difference was found in mean preoperative hemoglobin $(11.8 \pm 0.7)$ and postoperative hemoglobin $(10.9 \pm 0.8)$. No patient had postpartum hemorrhage requiring cesarean hysterectomy. Only two patient needed blood transfusion postoperatively. Mean time taken for surgery was $58.4 \pm 8.94$ minute and average duration of hospital stay was $6.7 \pm 1.6$.

Conclusions: With the advent of better anesthesia, easy availability of blood and blood component, cesarean myomectomy is safe surgical procedure when performed by experienced obstetrician in carefully selected patients.
\end{abstract}

Keywords: Cesarean, Fibroids, Myomectomy, Postpartum hemorrhage

\section{INTRODUCTION}

Uterine leiomyomas are benign tumer this arising from the muscle cells of uterus with an incidence ranging between 5.4 to $7.7 \% .^{1,2}$ The frequency of uterine myomas during pregnancy is $0.5-5 \% .^{3}$ During pregnancy leiomyoma usually remain asymptomatic, but they may be associated with increased frequency of spontaneous abortion, preterm lab this, premature rupture of membranes, antepartum bleeding, abruptio placenta, malpresentation and high incidence of cesarean delivery. Sometimes it may undergo red degeneration usually during second trimester of pregnancy. A pedunculated fibroid may undergo torsion. The impact of uterine myoma on pregnancy depends on size, number and localization of myoma. If it is located in lower uterine segment or cervix, it can lead to obstructed lab this or cervical dystocia. It can also lead to retained placenta, subinvolution of uterus, postpartum endomyometritis and Postpartum Haemorrhage in immediate postpartum period. ${ }^{4,5}$

The documented reasons for the removal of uterine fibroids during caesarean section include prevention of necrobiosis, unusual intraoperative protrusion of tumer this to gain access to the baby in patients in whom fibroids are located in lower uterine segment and when fibroids cause difficulty with uterine wound closure. ${ }^{6}$ 
If caesarean section and myomectomy are performed at the same time, risk of multiple surgeries, anaesthetic complications, exorbitant costs of operative procedure and hospital stay can be reduced. Myomectomy at the time of caesarean section also has increased risk of intractable haemorrhage, which may require hysterectomy and increased postoperative morbidity. ${ }^{7}$ It can be prevented by several techniques which minimize blood loss during caesarean myomectomy. The aim of this prospective study was to evaluate efficacy, safety and outcome of caesarean myomectomy in a series of patients.

\section{METHODS}

This ongoing study is underway at Sri Guru Ram Das University of Medical Sciences and Research, Amritsar, and patients from Feb. 2015-June 2018 were selected for the study. Myomectomy was performed during caesarean section in a total of 34 patients who were diagnosed to have fibroids by ultrasound in antenatal period and in those in whom myoma was incidently found during caesarean section.

Prior ethical approval for study was obtained from Medical Research and Ethics Committee of the Hospital. The informed consent was obtained from all the patients for possibility of postpartum haemorrhage and hysterectomy.

Information on demographic data including maternal age, parity, antenatal cthisse, gestational age at delivery and indication for caesarean section was recorded. All routine investigations, Platelet count, PTI were done. Prior arrangement for blood transfusion was made. All patients included in this study fulfilled following criteria 1) No history of antepartum haemorrhage; 2) No surgical procedure done apart from myomectomy; 3) No history of any preexisting bleeding disorders.

The patients were thoroughly counselled for possibility of successful removal of fibroid with a decision be done during surgery (caesarean section). In no case attempt to perform myomectomy was the indication for caesarean section.

During caesarean section after the delivery of baby uterine incision was first sutured. Then uterus was inspected for site, size and type of myoma and feasibility of removal of myoma was decided. An elliptical incision was given on base of subserous myoma and purse string suture was applied at the base piercing serosa and some depth of myometrium to secure hemostasis and myoma was enucleated. In case of intramural fibroids transverse or longitudinal incision was given over the surface of myoma and was enucleated. Hemostasis was also secured by using electrocautery and intravenous infusion of oxytocin was also ensured intraoperatively and postoperatively. The uterine incision was sutured in two to three layers using chromic catgut No. 1.
The fibroids removed were:

- All 6/7 as per FIGO classification.

- At 2 occasions $1 / 2$.

- In one or two cases 5/6 with medium to large size.

For present analysis data regarding number, location, size and type of fibroid, time required for surgery, blood loss and postoperative complications was obtained.

\section{RESULTS}

In this study thirty four patients underwent caesarean myomectomy from February 2015 to June 2018.

Table 1: Distribution of mothers according to Age, parity and gestational age.

\begin{tabular}{|lcl|}
\hline Parameters & Number $(\mathbf{n = 3 4})$ & Percentage \% \\
\hline Age (years) & & \\
\hline $20-25$ & 4 & 11.8 \\
\hline $26-30$ & 18 & 52.9 \\
\hline $31-35$ & 8 & 23.5 \\
\hline $36-40$ & 4 & 11.8 \\
\hline Parity & & \\
\hline 0 & 19 & 55.9 \\
\hline $1-2$ & 10 & 29.5 \\
\hline $3-4$ & 5 & 14.7 \\
\hline$>4$ & 1 & 2.9 \\
\hline Gestation age (weeks) & \\
\hline $31-34$ & 2 & 5.9 \\
\hline $35-38$ & 24 & 70.5 \\
\hline $39-42$ & 8 & 23.5 \\
\hline
\end{tabular}

Table 1 shows the obstetric characteristics (parity, gestational age). The age of patients was between 20 to 40 years and $55.9 \%$ patients were nullipara. $70.6 \%$ of patients undergoing myomectomy were between 35-38 weeks.

Table 2: Demonstrates the indication for caesarean section of the study patients $(n=34)$.

\begin{tabular}{|lll|}
\hline Indications & No. & Percentage \% \\
\hline Previous LSCS & 7 & 20.6 \\
\hline $\begin{array}{l}\text { Cephalopelvic } \\
\text { disproportion }\end{array}$ & 11 & 32.4 \\
\hline $\begin{array}{l}\text { Pregnancy induced } \\
\text { hypertension with IUGR }\end{array}$ & 5 & 14.7 \\
\hline Breech presentation & 4 & 11.8 \\
\hline Fetal distress & 4 & 11.8 \\
\hline Transverse lie & 2 & 5.8 \\
\hline $\begin{array}{l}\text { Previous myomectomy } \\
\text { with fibroid }\end{array}$ & 1 & 2.9 \\
\hline
\end{tabular}

Total number of fibroids removed were 58. Most of fibroids were sub serosal $(55.2 \%)$ and between $3-6 \mathrm{~cm}$ in size $(62 \%)$. Only 7 fibroids were more than $6 \mathrm{~cm} .38 \%$ 
fibroids were located in body of uterus. All fibroids removed were located on anterior wall of uterus except two patients where fibroid was located in posterior wall. Majority of fibroids $(65.59 \%)$ were located in body of uterus. Only $6(10.4 \%)$ fibroids were present in lower uterine segment. Prior knowledge of site and type of fibroids was known in $70 \%$ of cases and reconfirmed from serial ultrasound done in antenatal period. In $30 \%$ cases it was an accidental finding at caesarean section. One submucous fibroid popped out of posterior surface of uterine wall opposite the incision line and actually was not allowing closure of wound without removal. In another patient fibroid could be seen close to upper border of incision line and was tunneled out through same approach. Another sub serosal fibroid impacted in pouch of douglas was removed by eventration of uterus and disimpaction from culdesac.

Table 3: Depicts type, size and location of fibroids.

\begin{tabular}{|lll|}
\hline Parameter & Number $(\mathbf{n = 5 8})$ & Percentage \% \\
\hline Type of fibroid & & \\
\hline Subserosal & 32 & 55.2 \\
\hline Intramural & 22 & 37.9 \\
\hline Submucosal & 4 & 6.9 \\
\hline Size & & \\
\hline$<3 \mathrm{~cm}$ & 15 & 25.9 \\
\hline $3-6 \mathrm{~cm}$ & 36 & 62.1 \\
\hline$>6 \mathrm{~cm}$ & 7 & 12.0 \\
\hline Location & & \\
\hline Body & 38 & 65.5 \\
\hline Fundus & 14 & 24.1 \\
\hline $\begin{array}{l}\text { Lower uterine } \\
\text { segment }\end{array}$ & 6 & 10.4 \\
\hline
\end{tabular}

Table 4: Surgical outcome in study patients $(n=34)$.

\begin{tabular}{|ll|}
\hline Duration of surgery (minutes) & Mean \pm SD \\
\hline Amount of blood loss (cc) & $58.4 \pm 8.94$ \\
\hline Duration of hospital stay (days) & $600.2 \pm 104.2$ \\
\hline Preoperative $\mathrm{Hb}(\mathrm{g} / \mathrm{dl})$ & $6.7 \pm 1.6$ \\
\hline Postoperative $\mathrm{Hb}(\mathrm{g} / \mathrm{dl})$ & $11.8 \pm 0.7$ \\
\hline Frequency of blood transfusion & $10.9 \pm 0.8$ \\
\hline Incidence of post-operative fever & $5.9 \%$ \\
\hline
\end{tabular}

Mean duration of surgery was $58.4 \pm 8.94$ minutes. No significant change in preoperative and postoperative haemoglobin was found. Only 1 patient had fever in postoperative period and 2 patients required blood transfusion. No patient had postpartum haemorrhage requiring caesarean hysterectomy.

\section{DISCUSSION}

Caesarean myomectomy has traditionally been discharged due to fear of intractable haemorrhage and postoperative morbidity. If performed in carefully selected patients, it saves the patient, the ordeal of second admission to hospital. In addition the uterus in immediate postpartum phase is better adapted physiologically to control haemorrhage than at any other stage in woman's life. Hence it seems logical to perform caesarean myomectomy.

Recent studies have shown that caesarean myomectomy can be performed safely and successfully by an experienced obstetrician in carefully selected patients. Ehigiegba et al, conducted successful caesarean myomectomy on 25 patients and no patient required caesarean hysterectomy. ${ }^{8}$ In this study, caesarean myomectomy was performed in 34 patients and 58 fibroids were removed. The mean preoperative haemoglobin was $11.8 \pm 0.7 \mathrm{~g} / \mathrm{dl}$ and mean postoperative haemoglobin was $10.9 \pm 0.8 \mathrm{~g} / \mathrm{dl}$. No patient required caesarean hysterectomy and blood transfusion was needed in two patients.

Kaymak et al, compared 40 patients who had undergone myomectomy during caesarean section with 80 patients with myomas who underwent only caesarean section. ${ }^{9}$ The mean size of fibroids removed was $8.1 \mathrm{~cm}$. There was no significant difference in incidence of haemorrhage, postoperative fever or frequency of blood transfusion between two groups. In this study also out of 34 patients only two required blood transfusion and one patient had fever in postoperative period.

Various studies have described techniques to minimize blood loss during caesarean myomectomy e.g. uterine thorniest, bilateral uterine artery ligation and electrocautery. ${ }^{10,11}$ In this study we applied purse string sutures at the base, secured myoretraction by bimanual massage and intravenous infusion of high dose oxytocin was given to ensure uterine contraction during myomectomy and it was continued for 4-6 $\mathrm{h}$ this in postoperative period.

In this study, number of corporeal leiomyomas (65.5\%) were more as compared to those located in fundus $(24.1 \%)$. Only $10.4 \%$ were located in lower uterine segment. While myomectomy was conducted maximum fibroids were sub serosal in location $(55,29 \%)$ and only $4 \%$ were submucosal. One patient had $(12 \times 10 \mathrm{~cm})$ submucosal fibroid which projected out of incision line after delivery of baby, myomectomy was conducted to facilitate the closure of uterine incision. There were no intraoperative and postoperative complications.

A large subserous fibroid $(14 \times 12 \mathrm{~cm})$ was removed which was located on posterior wall of body of uterus and was impacted in pouch of douglas. Leanza et al, conducted a successful caesarean myomectomy in a large myoma of $22 \mathrm{~cm}$ diameter and $3000 \mathrm{gm}$ in weight. Yuddani et al, reported removal of $33.3 \times 28.8 \times 15.6 \mathrm{~cm}$ fibroid at caesarean section with intraoperative blood loss of $1860 \mathrm{ml}$ necessitating blood transfusion. ${ }^{12,13}$ 
Caesarean myomectomy was conducted by Incebiyik A et al, on 16 patients and average time taken for surgery was 56.1 minutes and all patients were discharged in satisfactory condition after average of 3.25 days postoperatively. ${ }^{14}$ In this study mean duration of surgery was $58.4 \pm 8.94$ minutes and average duration of hospital stay was $6.7 \pm 1.6$ days.

A study conducted by Roman and Tabsh suggested that caesarean myomectomy should be avoided in intramural myomas within fundus. ${ }^{15}$ Hassiakos et al, also recommended that caesarean myomectomy should be avoided in intramural myomas located in fundus and myomas located in cornua of uterus as they are associated with more surgical complications. ${ }^{16}$

In this study large intramural myomas, fundal intramural myomas located near cornual regions and seedling fibroids were not removed. (3-4 FIGO classification) In one patient uterus was studded with small fibroids ranging from $1-2 \mathrm{~cm}$ size and they were more than 100 in number. Only two fibroids of size $3-4 \mathrm{~cm}$ and $7-8 \mathrm{~cm}$ could be removed and others left in situ.

Although myomectomy during pregnancy should not be done, but during caesarean section, it is a successful undertaking ${ }^{17}$. Understanding hemostasis achievements, techniques, expertise, availability of blood components and expert anaesthetist are some of the essential requirements for undertaking caesarean myomectomy.

\section{Obstetrician perspective}

With each caesarean myomectomy successfully performed, one become more ready to handle next more challenging case. Patient's perspective: It is also rewarding as patient is relieved of stress and exhibits satisfaction and sense of wellbeing on knowing that one extra lifetime surgical procedure has been minimized.

\section{CONCLUSION}

Caesarean myomectomy can be recommended in selected patients in tertiary care centres in the hands of experienced obstetricians. Intraoperative assessment of fibroids is important in decision making for caesarean myomectomy. Fibroids obstructing lower uterine segment and accessible sub serosal fibroids can be safely removed. Intraoperative complications can be reduced by taking adequate measures to minimize blood loss like uterotonic drugs, uterine artery ligation, stepwise devascularisation and uterine artery embolization. Hence preservation of uterus should be aimed at by experienced obstetricians whenever it is feasible.

\section{Funding: No funding sources} Conflict of interest: None declared

Ethical approval: The study was approved by the Institutional Ethics Committee

\section{REFERENCES}

1. Lippman SA, Warner M, Samuels S, Olive D, Vercellini P, Eskenazi B. Uterine fibroids and gynecologic pain symptoms in a population-based study. Fertility Sterility. 2003 Dec 1;80(6):1488-94.

2. Flake GP, Andersen J, Dixon D. Etiology and pathogenesis of uterine leiomyomas: A review. Envir Health Perspect. 2003 Jun;111(8):1037-54.

3. Rasmussen KL, Knudsen HJ. Effect of uterine fibromas on pregnancy. Ugeskrift Laeger. 1994 Dec;156(51):7668-70.

4. Omigbodun AO, Fawole AO. Myomectomy during pregnancy and delivery: is it safe?: Commentary. Trop J Obstet Gynaecol. 2005;22(1):1-3.

5. Okoro O, Onwere S. Myomectomy during pregnancy. Pak J Med Scie. 2007 Oct 1;23(5):771-3.

6. Awoleke JO. Myomectomy during caesarean birth in fibroid-endemic, low-resource settings. Obstet Gynecol Int. 2013;2013.

7. Cunningham FG, Gant NF, Levenok KJ, Gilstrap LC, Hauth JC, Wenstrom KD. Abnormalities of the reproductive tract. In: Williams Obstetrics. $21^{\text {st }}$ ed. New York: McGraw Hill; 2001:930.

8. Ehigiegba AE, Ande AB, Ojobo SI. Myomectomy during cesarean section. Int J Gynecol Obstet. 2001 Oct;75(1):21-5.

9. Kaymak O, Ustunyurt E, Okyay RE, Kalyoncu S, Mollamahmutoglu L. Myomectomy during cesarean section. Int J Gynecol Obstet. 2005 May;89(2):90-3.

10. Sapmaz E, Celik H, Altungül A. Bilateral ascending uterine artery ligation vs. tourniquet use for hemostasis in cesarean myomectomy. A comparison. J Reprod Med. 2003 Dec;48(12):950-4.

11. Cobellis L, Florio P, Stradella L, Lucia ED, Messalli EM, Petraglia F, et al. Electro-cautery of myomas during caesarean section-two case reports. European J Obstet Gynecol Reprod Biol. 2002 Apr 10;102(1):98-9.

12. Leanza V, Fichera S, Leanza G, Cannizzaro MA. Huge fibroid (g. 3.000) removed during cesarean section with uterus preservation. A case report. Annali Italiani di Chirurgia. 2011;82(1):75-7.

13. Yuddandi N, Gleeson R, Gillan J, Geary $M$. Management of a massive caseous fibroid at caesarean section. J Obstet Gynaecol: J Inst Obstet Gynaecol. 2004 Jun;24(4):455-6.

14. Incebiyik A, Hilali NG, Camuzcuoglu A, Vural M, Camuzcuoglu H. Myomectomy during caesarean: a retrospective evaluation of 16 cases. Arch Gynecol Obstet. 2014;289(3):569-73.

15. Roman AS, Tabsh KM. Myomectomy at time of cesarean delivery: a retrospective cohort study. BMC Pregn Childbirth. 2004;4(1):14.

16. Hassiakos D, Christopoulos P, Vitoratos N, Xarchoulakou E, Vaggos G, Papadias K. Myomectomy during cesarean section: a safe procedure? Ann New York Acad Sci. 2006;1092(1):408-13. 
17. Fletcher H, Frederick J. Abdominal myomectomy revisited. Progr Obstet Gynaecol. 2005;16:277-86.
Cite this article as: Bala R, Kamal P, Nagapal M, Singh S. Current status of cesarean section myomectomy-prospective ongoing study. Int J Reprod Contracept Obstet Gynecol. 2019;8:3189-93. 